\title{
The Power-Energy Coupling Effect of Mixed Hard-Carbon/Graphite Anode
}

\author{
Yanli Yin ${ }^{1,2}$, Chao Shen ${ }^{1,2}$, Steven Yturriaga ${ }^{2}$, Jim P. Zheng ${ }^{3}$ \\ ${ }^{1}$ Department of Electrical and Computer Engineering, Florida A \& M University and Florida State University, Tallahassee, FL, \\ USA \\ ${ }^{2}$ Aero-Propulsion, Mechatronics and Energy Center, Florida State University, Tallahassee, FL, USA \\ ${ }^{3}$ Department of Electrical Engineering, University at Buffalo, The State University of New York, Buffalo, New York, USA \\ Email: *jzheng@buffalo.edu
}

How to cite this paper: Yin, Y.L., Shen, C., Yturriaga, S. and Zheng, J.P. (2021) The Power-Energy Coupling Effect of Mixed Hard-Carbon/Graphite Anode. Journal of Materials Science and Chemical Engineering, 9, 16-31.

https://doi.org/10.4236/msce.2021.91002

Received: November 12, 2020

Accepted: January 16, 2021

Published: January 19, 2021

Copyright $\odot 2021$ by author(s) and Scientific Research Publishing Inc. This work is licensed under the Creative Commons Attribution International License (CC BY 4.0).

http://creativecommons.org/licenses/by/4.0/ (c) (i) Open Access

\begin{abstract}
As the anode materials of lithium-ion battery, the hard carbon has the higher power performance while the graphite has the higher energy performance, respectively. In this work, novel mixed hard carbon/graphite anodes are presented showing the coupling effect of power and mixed anodes was investigated at the varying charging rates, showing the tunable behaviors dependent on the hard carbon/graphite ratios. By studying the specific capacity evolution in different split potential ranges, we found that the mixed anodes with a higher proportion of hard carbon were advantageous when working in the cut-off potential greater than $0.10 \mathrm{~V}$. The electrochemical impedance spectroscopy was measured at various anode potentials, which depicted the evolution of cell resistance with the state of charge. With the aid of electrochemical impedance spectroscopy, we found that the capacity evolution with mixed ratio is attributed to the lithiation-level induced difference of charge transfer resistance and Warburg resistance. A coupling effect was discovered showing a great potential in balancing the power-energy performance of mixed anode by simply controlling the ratio of hard-carbon/graphite.
\end{abstract}

\section{Keywords}

Lithium-Ion Battery, Graphite, Hard Carbon, Power, Energy

\section{Introduction}

Graphite has been commercialized as anode active material of lithium (Li) ion batteries for years because it has the merits of high reversible capacity (370 $\mathrm{mAh} / \mathrm{g}$ ) and excellent cycling performance with the formation of stable solid 
electrolyte interphase (SEI) during cycles [1] [2]. However, graphite has the limited rate performance that cannot support the higher power need of the next generation Li-ion batteries [3] [4]. Moreover, graphite is not well matched with the high power cathodes such as active carbon in the newly developed Li-ion capacitors for higher power application [5] [6].

In addition to graphite, a series of carbon material such as soft carbon [7], hard carbon [8], were investigated as the anodes of Li-ion batteries. Among all the candidates, the hard carbon is promising with various merits. First, compared with the parallel aligned structure of graphite, the hard carbon has more porous, random, and small-dimensional graphene layers. As the hard carbon has different physical properties with graphite, Li ion can intercalate in layered carbons such as graphite, and it adsorbs on the surfaces of single carbon layers in hard carbons. The adsorbing shows a higher rate than the intercalating. Therefore, the disordered structure of hard carbon is more capable of Li-ion accommodation which can contribute to the higher power performance at high rate [9]. Second, compared with graphite, the structural stability of hard carbon results in the better cycling performance. The significant deformation of the graphite electrode is from the expansion and shrinkage of d002 spacing during charge and discharge cycles resulting in poor cycling performance, while the d002 spacing of hard carbon is large enough for the Li doping without leading to electrode expansion [10]. However, the major drawback of hard carbon is the relatively higher irreversible capacity loss during the first cycle compared with the graphite, because hard carbon with the higher porosity consumes more Li-ions in electrolyte for formation of SEI. Moreover, compared with graphite, the commercialized hard carbon shows higher cost and lower specific capacity which is not efficient for the large quantity of application.

Researchers have kept studying the use of hard carbon with higher power performance as the alternative of graphite, but the lower energy density limits its wide use in Li-ion chemistry [11]. Based on the differences of energy-power performance between graphite and hard carbon, the combination of these two materials has shown some promising characteristics in Li-ion system [12] [13]. By adding the graphite particles into the hard carbon, the modified anode shows an improved packing density and a higher anode specific capacity compared with the porous hard carbon [14]. Moreover, by adding the hard carbon into graphite, the modified anode gains more porous channels for ion transportation and a higher power performance compared with graphite [15]. On the other hand, the state of charge (SOC) of Li-ion batteries is usually monitored by the cell voltage change. Because the graphite has a dramatic platform voltage profile, the SOC is highly sensitive to the minor change of open circuit voltage (OCV). This issue becomes even more severe when graphite anode is coupled with the $\mathrm{Li}$ iron phosphate cathode which also has a very flat platform. Hence, the hard carbon was added to the graphite electrodes to introduce more sloping features to the voltage profile which improved the sensitivity of OCV-SOC relationship [16]. 
Despite the recent research efforts, the mechanism of coupling the hard carbon and the graphite is still not well understood. The previous research focused on the material modifying technology to couple the hard carbon and graphite but did not pay many efforts to searching proper methods to study the mechanism in coupling hard carbon and graphite. The biggest difficulties in understanding more deeply the coupling between graphite and hard carbon include the well-designed electrochemical experiments, more accurate measurement of electrode potential, resistance. A well-designed three-electrode measurement and systematic analysis are needed to address the coupling effect of energy and power performance based on the mixed hard carbon/graphite anodes. A well analyzed results and modeling of electrochemical impedance spectroscopy are needed to analyze the resistance evaluation in coupling hard carbon and graphite.

In this work, we constructed a series of mixed anodes with various ratios of hard carbon: graphite, and carefully studied the effect of hard-carbon: graphite ratio on their coupling electrochemical properties. The coupling effect of energy and power is investigated through some new perspective routes, including the characteristics of rate performance of anodes during the split potential range. The electrochemical impedance spectroscopy (EIS) was measured at various anode potentials and analyzed quantitatively to depict the evolution of cell resistance varying with the state of charge (SOC).

\section{Experimental}

\subsection{The Fabrication of Mixed Anodes}

A series of mixed anodes with various ratios of hard carbon/graphite were made through the following wet method. First, we obtained a slurry of carbon active material and Polyvinylidene fluoride binder (PVDF, HSV 900, Arkema Co.) with the ratio at 94:6 dissolved in N-Methyl-2-pyrrolidone solvent (NMP, Sigma-Aldrich). The active materials were mixtures of hard carbon (Carbotron: $\mathrm{P}$, Kureha Co.) and graphite (MGS, China aviation Li-ion battery Co.) with quantities at $10.0 \mathrm{~g}: 0 \mathrm{~g}, 7.5 \mathrm{~g}: 2.5 \mathrm{~g}, 5.0 \mathrm{~g}: 5.0 \mathrm{~g}, 2.5 \mathrm{~g}: 7.5 \mathrm{~g}$, and $0 \mathrm{~g}: 10.0 \mathrm{~g}$ to achieve the ratios at 100:0, 75:25, 50:50, 25:75, and 0:100, respectively. We use the ball milling method to achieve the slurry mixing: the weight ratio of solvent: solid is $14 \mathrm{~g}: 10 \mathrm{~g}$; the ball number is 15 with average diameter of $10 \mathrm{~mm}$ and average weight of $1.4 \mathrm{~g}$; the rotating speed: $180 \mathrm{c} / \mathrm{min}$; the rotating time is 6 hours. Second, we blade-coated slurry on a $\mathrm{Cu}$ foil with the thickness of $10 \mu \mathrm{m}$ followed by drying in air at room temperature for 12 hours. Third, the obtained anode sheets were dried again in constant flowing air at the temperature of $80^{\circ} \mathrm{C}$ for 12 hours. Then, the anode sheets were compressed to the same thickness by a heat-rolling mill method. Finally, the anode sheets were punched into round size with an area of $1.27 \mathrm{~cm}^{2}$ and dried at $120^{\circ} \mathrm{C}$ for 12 hours inside a vacuum oven. Here, all the anodes have the same electrode thickness and area so that no thickness or geometry difference will affect the electrode performance [17] [18]. 


\subsection{The Characterization of Mixed Anodes}

The Brunauer-Emmett-Teller (BET) surface area of the mixed anodes was measured through the nitrogen adsorption-desorption isotherms (Autosorb-iQ, Quantachrome Instruments, USA). The pore size distributions of all the anodes were analyzed based on the Barett-Joyner-Halenda (BJH) method. The microstructural analysis of the mixed anodes was carried out by a Field Emission Scanning Electron Microscope (FE-SEM, JSM-7401F, JEOL, USA). The electrical conductivity of the mixed anodes was measured by the 4-probe method. For this measurement, the powder of active materials was pressed to disks with the diameter of $1 / 2$ inch by the pressing tools.

\subsection{The Construction of the Three-Electrode Cells for the Mixed Anodes}

Because the overpotential will dramatically affect the electrode potential in the charge-discharge measurement, a three-electrode cell was constructed to monitor the real electrode potential of mixed anodes (see Figure 1) [19]. First, the fabricated mixed anodes with various ratios were used as working electrodes. Second, a Li foil with the thickness at $0.25 \mathrm{~mm}$ was punched to a round size with the area at $1.60 \mathrm{~cm}^{2}$ and used as the counter electrode. Third, to form a reference electrode, a Li slice with a square size of $2 \mathrm{~mm} \times 2 \mathrm{~mm}$ was cut off from the same $\mathrm{Li}$ foil, and then compressed on one tip of a $10 \mu \mathrm{m}$-thick $\mathrm{Cu}$ strip with the rectangular size of $3 \mathrm{~mm} \times 20 \mathrm{~mm}$. As Costard et al. reported [20], the geometries of the reference electrodes will greatly affect the results of the three-electrode system testing, so we kept all the reference electrodes at consistent geometries in our cells.

We used the commercial electrolyte with $1 \mathrm{~mol} / \mathrm{L} \mathrm{LiPF6}$ in ethylene carbonate (EC): dimethyl carbonate (DMC) with the ratio at 1:1 by weight (LP30, Badische Anilin-und Soda-Fabrik, USA). Two pieces of glass microfiber filters (Whatman, GE Healthcare Life Sciences, USA) with the thickness at $0.26 \mathrm{~mm}$ were punched to a round size with the area at $1.98 \mathrm{~cm}^{2}$ as the separator.

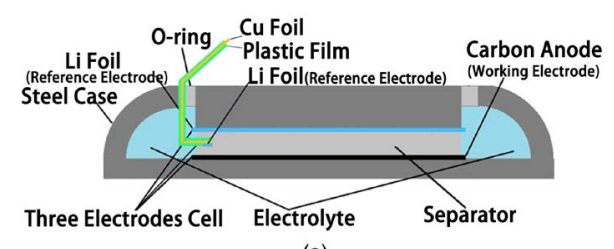

(a)

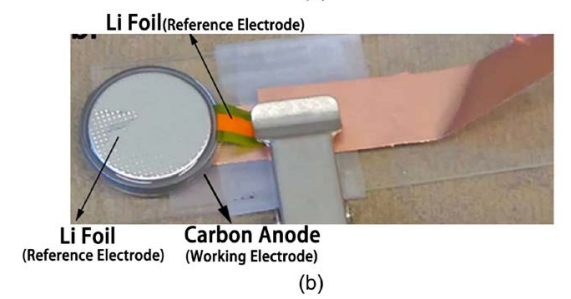

Figure 1. The structure of the three-electrode cell: (a) schematic diagram, (b) Digital photo. 
A coin cell (CR2032) was finally assembled containing all above items. Here, two pieces of $10 \mu \mathrm{m}$-thick plastic paper with the rectangular size of $4 \mathrm{~mm} \times 15$ $\mathrm{mm}$ were used as the insulator to separate the reference electrodes with the steel coin cases. 3 pieces of $0.5 \mathrm{~mm}$-thick steel spacers and 1 piece of $0.3 \mathrm{~mm}$-thick steel spring were used to keep every cell at constant internal pressure.

\subsection{The Characterization of the Three-Electrode Cells for the Mixed Anodes}

The voltage profile at different rates was obtained from the cells by the galvanostatic charge-discharge testing (BTS3000, Neware Technology, China). Here we setup the three-electrode cell testing by giving current through working electrode and counter electrode and monitoring the cutoff voltage between the working electrode and the reference electrode.

The EIS curves were separately measured for the cells (Reference 3000, Gamry Instruments, USA). We used the same method as described above for initial SEI formation. After that, all the cells were charged at $0.1 \mathrm{C}$ to various potentials ranging from $1.00 \mathrm{~V}$ to $0.01 \mathrm{~V}$, then charged at constant-voltage until the current reduced to $10 \%$ of the $0.1 \mathrm{C}$ current, respectively. Cells were rested for 6 hours at the final OCV. Finally, cells were tested at the galvanostatic model with the frequency range from $0.01 \mathrm{~Hz}$ to $1 \mathrm{M} \mathrm{Hz}$, the $\mathrm{AC}$ current at $0.1 \mathrm{~mA}$, and DC current at $0 \mathrm{~V}$. To reduce the surrounding electromagnetic interference, the positive and negative wires of analyzers were twisted in a pair.

\section{Results and Discussion}

\subsection{The Porosity of Mixed Anodes}

The final anode parameters are listed in Table 1 . With increasing hard carbon content, the density of mixed anode decreases from $1.23 \mathrm{~g} / \mathrm{cm}^{3}$ to $0.94 \mathrm{~g} / \mathrm{cm}^{3}$,

Table 1. Characterizations of the electrode parameters for the three-electrode cells. Hard Carbon (HC), Graphite (G).

\begin{tabular}{|c|c|c|c|c|c|c|c|c|c|}
\hline \multirow[b]{2}{*}{ Ratio } & \multirow[b]{2}{*}{$\begin{array}{l}\text { Weight } \\
(\mathrm{mg})\end{array}$} & \multicolumn{3}{|c|}{ Working Electrodes } & \multirow[b]{2}{*}{$\begin{array}{c}\text { Porosity } \\
\text { (\%) }\end{array}$} & \multicolumn{2}{|c|}{ Counter Electrodes } & \multicolumn{2}{|c|}{$\begin{array}{l}\text { Reference } \\
\text { Electrodes }\end{array}$} \\
\hline & & $\begin{array}{c}\text { Thickness } \\
(\mu \mathrm{m})\end{array}$ & $\begin{array}{l}\text { Area } \\
\left(\mathrm{cm}^{2}\right)\end{array}$ & $\begin{array}{l}\text { Density } \\
\left(\mathrm{g} / \mathrm{cm}^{3}\right)\end{array}$ & & $\begin{array}{l}\text { Area } \\
\left(\mathrm{cm}^{2}\right)\end{array}$ & $\begin{array}{c}\text { Thickness } \\
(\mu \mathrm{m})\end{array}$ & $\begin{array}{l}\text { Area } \\
\left(\mathrm{cm}^{2}\right)\end{array}$ & $\begin{array}{c}\text { Thickness } \\
(\mu \mathrm{m})\end{array}$ \\
\hline $\begin{array}{l}\text { HC: } G \\
(100: 0)\end{array}$ & 7.1 & 59 & 1.27 & 0.94 & $57 \%$ & 1.60 & 250 & 0.04 & 100 \\
\hline $\begin{array}{l}\text { HC: } \mathrm{G} \\
(75: 25)\end{array}$ & 7.4 & 58 & 1.27 & 0.99 & $55 \%$ & 1.60 & 250 & 0.04 & 100 \\
\hline $\begin{array}{l}\text { HC: G } \\
(50: 50)\end{array}$ & 7.9 & 60 & 1.27 & 1.05 & $52 \%$ & 1.60 & 250 & 0.04 & 100 \\
\hline $\begin{array}{l}\text { HC: G } \\
25: 75)\end{array}$ & 8.6 & 59 & 1.27 & 1.15 & $48 \%$ & 1.60 & 250 & 0.04 & 100 \\
\hline $\begin{array}{l}\text { HC: G } \\
(0: 100)\end{array}$ & 9.2 & 60 & 1.27 & 1.23 & $44 \%$ & 1.60 & 250 & 0.04 & 100 \\
\hline
\end{tabular}


while the porosity increases from $44 \%$ to $57 \%$. This result shows that the addition of hard carbon can tune the density and porosity of the mixed anodes. The SEM images are given to characterize the anode morphology as shown in Figure 2. The particles show the size in tens of $\mu \mathrm{m}$ and the homogeneous distribution. The microstructure of hard carbon shows a sharp edge (Figure 2(a), Figure 2(b)), while the graphite shows close-to-round shapes (Figure 2(i), Figure 2(j)). More geometry space may form between hard carbon particles with sharp edges compared with the close-to-round graphite particles. This difference can possibly result in the porosity variation with the hard carbon content change in Table.

A detailed characterization of porosity is given by BET test as shown in Figure 3. From N2 adsorption-desorption in Figure 3(a), all the mixed anodes show Type IV isotherm according to the IUPAC classification, which is typical for
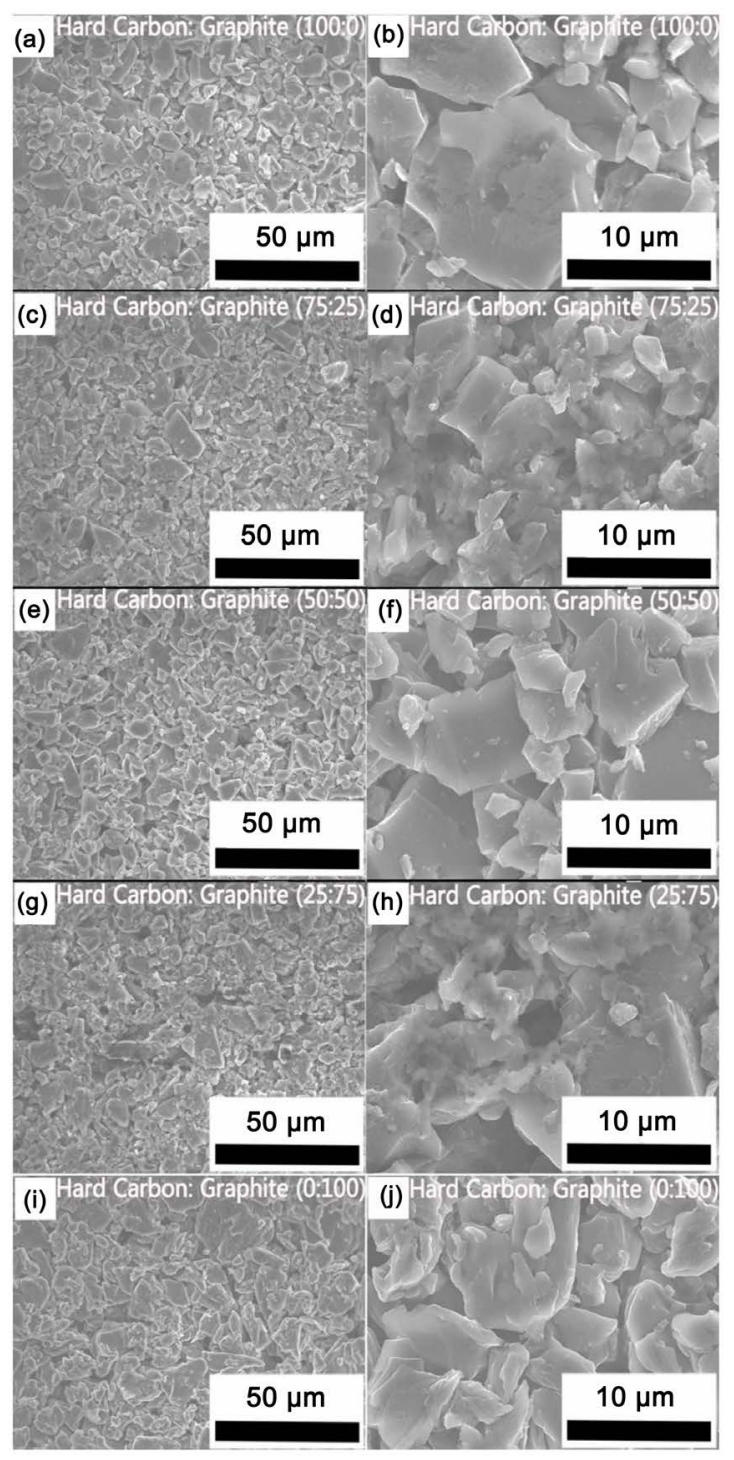

Figure 2. The SEM of mixed anodes with various hard carbon (HC): graphite $(\mathrm{G})$ ratios at ((a), (b)) 100:0, ((c), (d)) 75:25, ((e), (f)) 50:50, ((g), (h)) 25:75 and ((i), (j)) 0:100, respectively. 


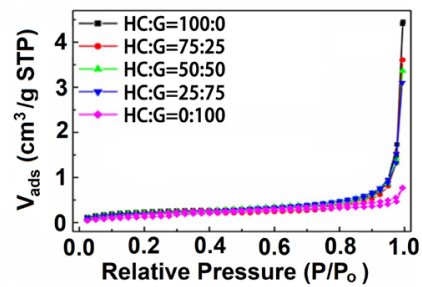

(a)

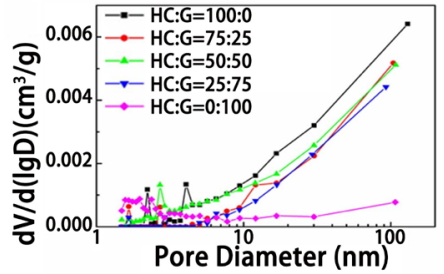

(b)

Figure 3. The BET results of mixed anodes. (a) N2 adsorption-desorption isotherms, (b) Pore size distributions.

mesoporous materials. These isotherms have classical hysteresis loops which are associated with the occurrence of pore condensation. The initial low P/P0 part of the isotherms have inflection points that can be attributed to monolayer-multilayer adsorption. From the isotherm, the specific surface areas were calculated as $0.827,0.785,0.761,0.633$ and $0.478\left(\mathrm{~m}^{2} / \mathrm{g}\right)$ for hard carbon: graphite ratios at 100:0, 75:25, 50:50, 25:75 and 0:100, respectively. The specific surface area increases with the hard carbon content, which is consistent with the calculated porosity in Table 1 and particle microstructure in Figure 2. From Figure 3 b, all the anodes show the very low content of pores with pore size less than 2 $\mathrm{nm}$. In the range of pore size higher than $2 \mathrm{~nm}$, the pore volume increases more dramatically with the hard carbon content, which shows that hard carbon can introduce more meso-pores into the anodes. The more porous structure of mixed anode with higher hard carbon content is more capable of ions transportation, which contributes to the potential of the higher power performance as reported in literature [9].

\subsection{The Electrical Conductivity of the Mixed Anodes}

As shown in Figure 4, the electrical conductivity of mixed anodes changes from $0.48( \pm 0.03) \mathrm{S} / \mathrm{cm}$ to $42.57( \pm 11.13) \mathrm{S} / \mathrm{cm}$ with the hard carbon: graphite ratio changing from 100:0 to 0:100. This result shows that graphite has better electrical conductivity than that of hard carbon. The effect of hard carbon addition on cell ohmic resistance will be discussed in the Section 3.3 of this article. We measured the conductivity at the constant room temperature.

\subsection{The Rate Performance Comparisons of the Mixed Anode Cells}

Before being tested at various rates, cells were first tested at $0.05 \mathrm{C}$ current for 1 cycle based on the theoretical specific capacity (graphite $372 \mathrm{mAh} / \mathrm{g}$, hard Carbon $210 \mathrm{mAh} / \mathrm{g}$ ). Then, cells were cycled at $0.1 \mathrm{C}$ for 3 cycles for well-formation of solid electrolyte interface (SEI) on the surface of the anode. Finally, cells were 


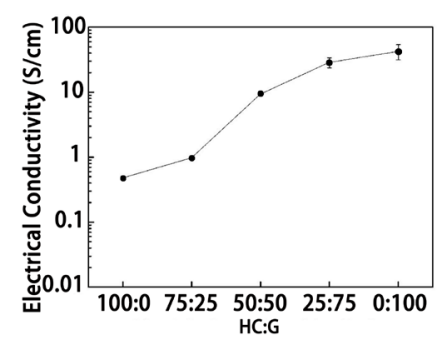

Figure 4. The electrical conductivity of the mixed anodes.

tested at varying C-rate currents. After the first few cycles of discharge and charge, the reversible capacity of graphite at the rate of $0.1 \mathrm{C}(280 \mathrm{mAh} / \mathrm{g})$ is comparably lower than the theoretical specific capacity of graphite $(372 \mathrm{mAh} / \mathrm{g})$ but is still higher than that of hard carbon $(210 \mathrm{mAh} / \mathrm{g})$. During the full intercalation of $\mathrm{Li}$-ion with the potential ranging from $1.50 \mathrm{~V}$ to $0.01 \mathrm{~V}$, the potential profile as a function of specific capacity of mixed anode with various hard-carbon: graphite ratios at rates ranging from $0.1 \mathrm{C}$ to $10 \mathrm{C}$ were shown in Figures 5(a)-(h). Here, $0.1 \mathrm{C}$ is defined as the rate with the time of $\mathrm{Li}$-ion intercalation at around 10 hours, and other rates are calculated accordingly. Because the potential profiles of mixed anodes with higher ratio of hard-carbon: graphite are more sloping, the average potential increases with the ratio of hard carbon: graphite. The higher average potential gives larger driving force for Li-ion migration which results in a faster $\mathrm{Li}$ intercalation into the anodes. This contributes to the higher rate performance of mixed anode by increasing the hard carbon: graphite ratio. As summarized in Figure 5(i), the anodes show decreasing specific capacity with the increasing hard carbon content at low rates ranging from $0.1 \mathrm{C}$ to $0.2 \mathrm{C}$, and the profile is reversed at high rates ranging from $0.5 \mathrm{C}$ to $10 \mathrm{C}$. Hence, a reversal point should exist between $0.2 \mathrm{C}$ and $0.5 \mathrm{C}$ for the specific capacity of mixed anodes changing with the hard carbon content.

The rate performance that is shown in Figure 5 is based on the full intercalation of Li-ion into anodes during the potential range starting from $1.50 \mathrm{~V}$ and ending at $0.01 \mathrm{~V}$ that is very close to $0 \mathrm{~V}$. However, in the real batteries, it is not necessary to force the anodes to a potential close to $0 \mathrm{~V}$ when the $\mathrm{Li}$ dendrites are easy to grow on the anodes, which could cause the short-circuit of batteries. Because the graphite anode has a wide potential platform close to $0 \mathrm{~V}$, the $\mathrm{Li}$ dendrites will be easy to grow at most of the potential range. In contrast, the hard carbon anode has a sloping curve with a small potential range close to $0 \mathrm{~V}$, so the potential range that is suitable for Li dendrites growing will be shrinking by the addition of hard carbon into graphite. Hence, it is safer to only use a partial potential range of the mixed anode for the best-balanced performance of energy and power. To further address this issue, a detailed analysis is carried out through comparing the rate performance within a series of anode potential range. Figures 6(a)-(d) show the specific capacity as the function of the rate for the mixed anodes with various hard carbon: graphite ratio based on a series of the potential range starting from $1.50 \mathrm{~V}$ and ending at $1.00 \mathrm{~V}$ (Figure $6(\mathrm{a})), 0.50 \mathrm{~V}$ 


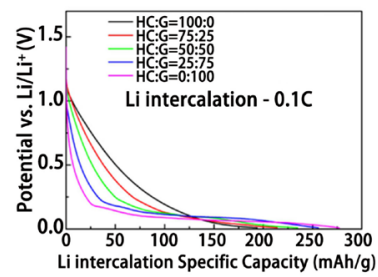

(a)

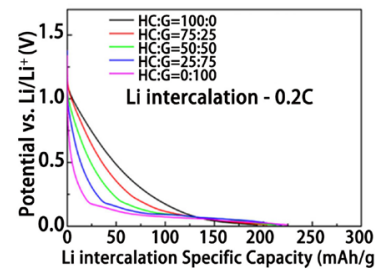

(b)

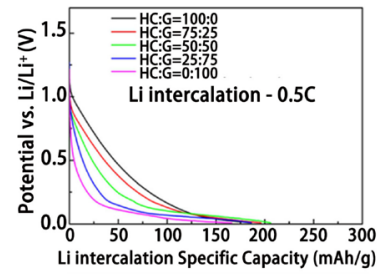

(c)

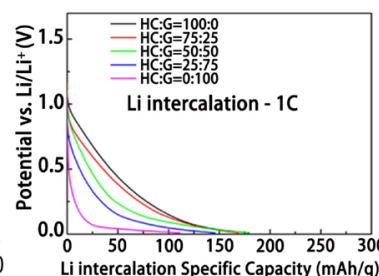

(d)

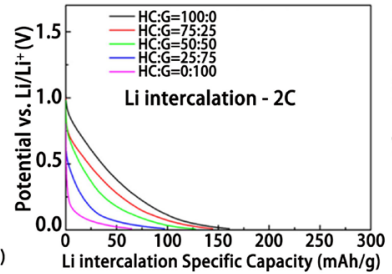

(e)

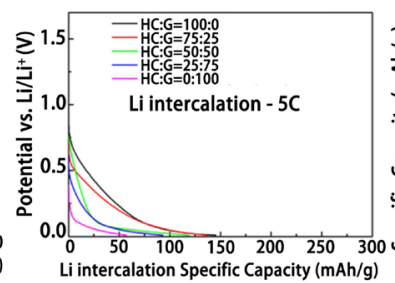

(f)

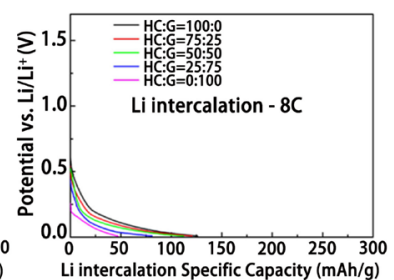

(g)

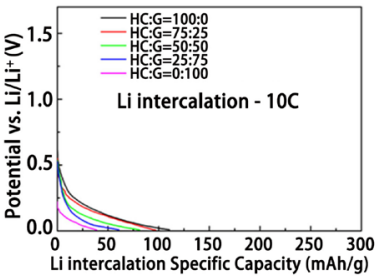

(h)

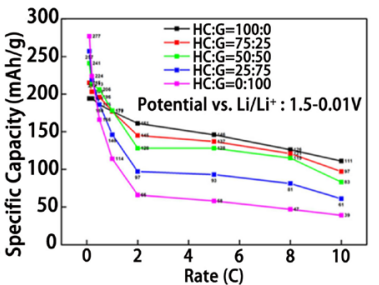

(i)

Figure 5. The $\mathrm{Li}$ intercalation voltage-specific capacity profile of mixed anode cells at various rates of (a) $0.1 \mathrm{C}$, (b) $0.2 \mathrm{C}$, (c) $0.5 \mathrm{C}$, (d) $1 \mathrm{C}$, (e) $2 \mathrm{C}$, (f) $5 \mathrm{C}$, (g) $8 \mathrm{C}$ and (h) $10 \mathrm{C}$, respectively. (i) The specific capacity-rate of all the cells. The Working electrode (WE), Reference electrode (RE).

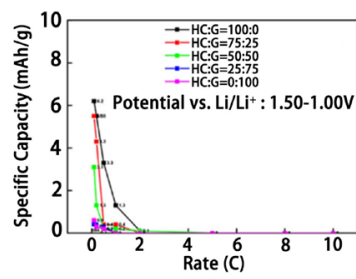

(a)

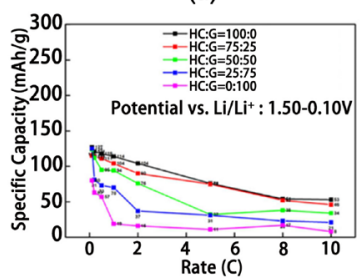

(d)

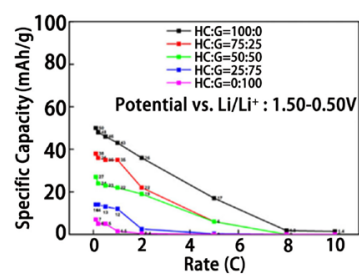

(b)

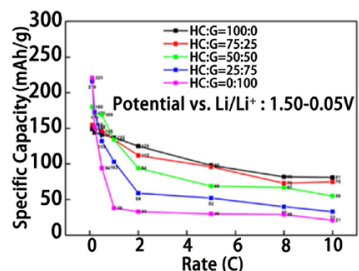

(e)

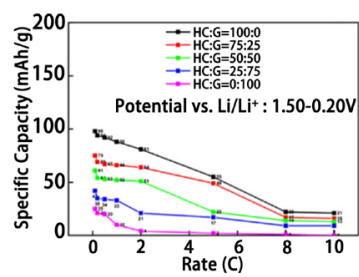

(c)

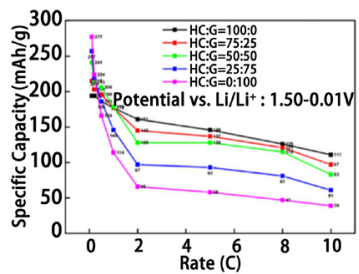

(f)

Figure 6. The specific capacity-rate relationship in different divided potential range from $1.50 \mathrm{~V}$ to (a) $1.00 \mathrm{~V}$, (b) $0.50 \mathrm{~V}$, (c) $0.20 \mathrm{~V}$, (d) $0.10 \mathrm{~V}$, (e) $0.05 \mathrm{~V}$ and (f) $0.01 \mathrm{~V}$, respectively.

(Figure 6(b)), $0.20 \mathrm{~V}$ (Figure 6(c)), and 0.10 V (Figure 6(d)), respectively. The mixed anodes with higher hard carbon: graphite ratio show the higher specific capacity at all rates ranging from $0.1 \mathrm{C}$ to $10 \mathrm{C}$. Figure 6(e) and Figure 6(f) show the specific capacity as the function of the rate based on the potential range starting from $1.50 \mathrm{~V}$ and ending at $0.05 \mathrm{~V}$ (Figure 6(e)) and $0.01 \mathrm{~V}$ (Figure 
6(f)), respectively. Being different from Figures 6(a)-(d), the mixed anodes in Figure $6(\mathrm{e})$ and $\mathrm{f}$ show the lower specific capacity with increasing hard carbon: graphite ratio at the low rates ranging from $0.1 \mathrm{C}$ to $0.2 \mathrm{C}$, while the specific capacity is higher with increasing hard carbon: graphite ratio at the high rates ranging from $0.5 \mathrm{C}$ to $10 \mathrm{C}$.

The rate performance dependence on the ratio of hard carbon: graphite may be attributed to the impedance evolution with the ratio. Figures 7(a)-(f) show the Nyquist plots of mixed anodes with various hard carbon: graphite based on various potential at $1.00 \mathrm{~V}, 0.50 \mathrm{~V}, 0.20 \mathrm{~V}, 0.10 \mathrm{~V}, 0.05 \mathrm{~V}$, and $0.01 \mathrm{~V}$, respectively, corresponding to the ending potentials in Figure 6.

The difference of Nyquist plots is visible but needs to be quantified, so the Nyquist plots were fitted by the equivalent circuit model in Figure 8. Here, Rs shows the ohmic resistance of cell from its electrolyte, separator, and electrical contacts, etc. The in-series units of $C_{1}-R_{1}, C_{2}-R_{2}$ and $C_{3}-R_{3}$ show the migration of Li-ion through SEI multi-layers. Both $C_{d l}$ (double layer capacitance) and $R_{c t}$ (charge transfer resistance) show the charge transfer kinetics at the electrode/electrolyte interface. $Z_{w}$ (Warburg element) shows the ion diffusion in the electrodes, which resembles the property of a constant phase element. The Warburg element is calculated according to

$$
\begin{gathered}
Z_{w}=R_{w} \frac{\operatorname{coth}\left(i \omega \tau_{W}\right)^{p}}{\left(i \omega \tau_{W}\right)^{p}} \\
\tau_{W}=R_{w} \times C_{W}
\end{gathered}
$$

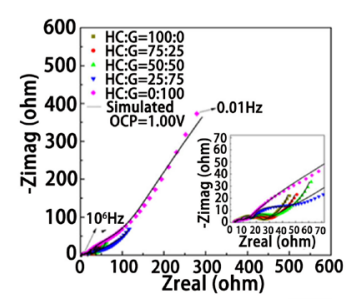

(a)

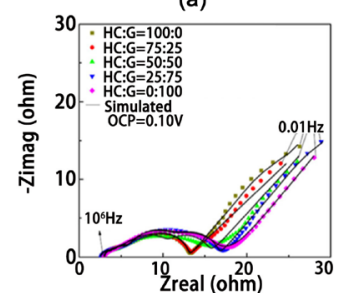

(d)

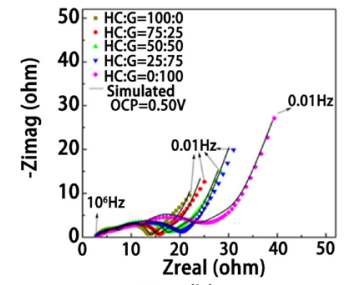

(b)

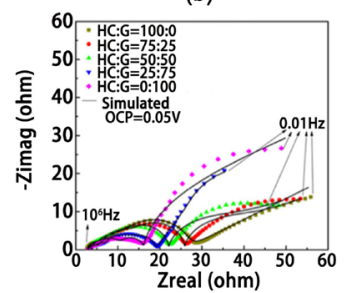

(e)

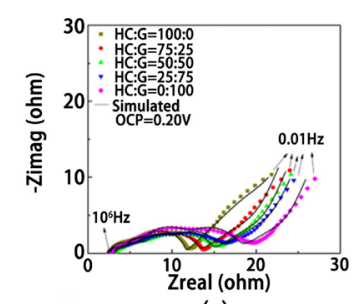

(c)

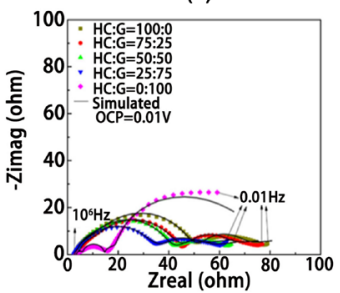

(f)

Figure 7. The Nyquist plots with fitted curves in different splited potential ranging from $1.50 \mathrm{~V}$ to (a) $1.00 \mathrm{~V}$, (b) $0.50 \mathrm{~V}$, (c) $0.20 \mathrm{~V}$, (d) $0.10 \mathrm{~V}$, (e) $0.05 \mathrm{~V}$ and (f) $0.01 \mathrm{~V}$, respectively.

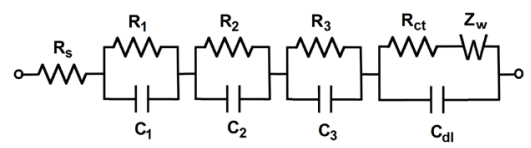

Figure 8. The equivalent circuit model used for the Nyquist plots fitting. 
where $R_{W}$ is the Warburg ion impedance, $\tau_{W}$ is the characteristic diffusion time constant, $\omega$ is the angular frequency of the applied AC signal, $C_{W}$ is the differential capacitance associated with the intercalation process at the low frequency, and $p$ denotes the finite space behavior or porosity of the electrode. As shown in Figure 7, all the fitting curves are well matched with the Nyquist plots, which ensures the data reliability.

As listed in Table 2, a summary of fitting parameters with the open circuit potential (OCP) at $1.00 \mathrm{~V}$ is shown as an example at which the anode is in state lack of Li. The Rs and the resistances and capacitances of SEI multi-layers $\left(R_{j}, j=\right.$ $1,2,3)$ are similar for different hard carbon-graphite ratios showing that the addition of hard carbon into graphite anodes does not increase the ohmic resistance of contacts in electrodes, even though hard carbon has a lower electrical conductivity than graphite. Meanwhile, the difficulty of Li-ion migration in SEI also does not change. However, $R_{c t}$ and $R_{w}$ decrease with increasing ratio of hard carbon: graphite. This result shows that the addition of hard carbon into graphite anodes can promote the charge transfer kinetics at the electrode/electrolyte interface and enhance the ion diffusion in the electrodes.

By summarizing all the fitting parameters at a series of ending potential, we give Figure 9 to compare the charge transfer resistance of the mixed anodes. At the ending potential of $1.00 \mathrm{~V}, 0.50 \mathrm{~V}$, and $0.20 \mathrm{~V}$, respectively, the anode has lower charge transfer resistance with increasing ratio of hard carbon: graphite. At the ending potential of $0.10 \mathrm{~V}$, the anode has the same charge transfer resistance with various ratios of hard carbon: graphite. At the ending potential of $0.05 \mathrm{~V}$ and $0.01 \mathrm{~V}$, the anode has higher charge transfer resistance with increasing hard carbon: graphite.

By summarizing all the fitting parameters at a series of ending potential, we give Figure 10 to compare the Warburg resistance of the mixed anodes. At the ending potential of $1.00 \mathrm{~V}$ and $0.50 \mathrm{~V}$, respectively, the anode has lower

Table 2. Summary of fitting parameters for the cells with mixed anodes at the OCP of $1.00 \mathrm{~V}$.

\begin{tabular}{|c|c|c|c|c|c|c|c|c|c|c|c|c|}
\hline \multirow[b]{2}{*}{ Ratio } & \multirow{2}{*}{$\begin{array}{c}\text { Ohmic } \\
R_{\mathrm{s}} \\
(\Omega)\end{array}$} & \multicolumn{6}{|c|}{ SEI layers } & \multicolumn{2}{|c|}{ Charge Transfer } & \multicolumn{3}{|c|}{ Warburg $\left(Z_{\mathrm{w}}\right)$} \\
\hline & & $\begin{array}{r}C_{1} \\
(\mathrm{~F})\end{array}$ & $\begin{array}{c}R_{1} \\
(\Omega)\end{array}$ & $\begin{array}{l}C_{2} \\
(\mathrm{~F})\end{array}$ & $\begin{array}{c}R_{2} \\
(\Omega)\end{array}$ & $\begin{array}{r}C_{3} \\
(\mathrm{~F})\end{array}$ & $\begin{array}{c}R_{3} \\
(\Omega)\end{array}$ & $\begin{array}{l}C_{\mathrm{dl}} \\
(\mathrm{F})\end{array}$ & $\begin{array}{c}R_{\mathrm{ct}} \\
(\Omega)\end{array}$ & $\begin{array}{c}R_{\mathrm{w}} \\
(\Omega)\end{array}$ & $\begin{array}{l}T_{\mathrm{w}} \\
\text { (s) }\end{array}$ & $p$ \\
\hline $\begin{array}{l}\text { HC: G } \\
(100: 0)\end{array}$ & 2.8 & $5.6 \times 10^{-7}$ & 1.5 & $3.4 \times 10^{-6}$ & 3.7 & $2.2 \times 10^{-5}$ & 8.9 & $2.7 \times 10^{-4}$ & 6.9 & 43.0 & 35.8 & 0.4 \\
\hline $\begin{array}{l}\text { HC: G } \\
(75: 25)\end{array}$ & 4.3 & $6.0 \times 10^{-7}$ & 1.5 & $2.7 \times 10^{-6}$ & 4.8 & $4.1 \times 10^{-5}$ & 6.8 & $6.1 \times 10^{-4}$ & 9.2 & 52.6 & 48.6 & 0.4 \\
\hline $\begin{array}{l}\text { HC: G } \\
(50: 50)\end{array}$ & 3.8 & $7.3 \times 10^{-7}$ & 1.8 & $3.5 \times 10^{-6}$ & 4.4 & $4.9 \times 10^{-5}$ & 6.4 & $7.2 \times 10^{-4}$ & 11.5 & 74.5 & 46.3 & 0.4 \\
\hline $\begin{array}{l}\text { HC: G } \\
(25: 75)\end{array}$ & 3.5 & $5.6 \times 10^{-7}$ & 2.2 & $4.2 \times 10^{-6}$ & 4.2 & $5.9 \times 10^{-5}$ & 7.1 & $7.5 \times 10^{-4}$ & 17.7 & 215.1 & 85.9 & 0.4 \\
\hline $\begin{array}{l}\text { HC: G } \\
(0: 100)\end{array}$ & 3.2 & $5.6 \times 10^{-7}$ & 1.4 & $3.1 \times 10^{-6}$ & 3.1 & $3.7 \times 10^{-5}$ & 3.1 & $5.9 \times 10^{-3}$ & 20.4 & 260.2 & 18.4 & 0.4 \\
\hline
\end{tabular}




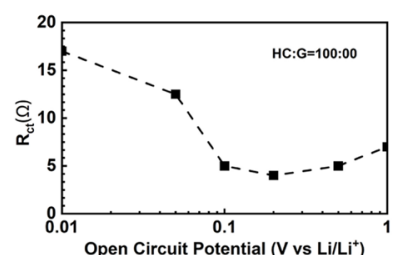

(a)

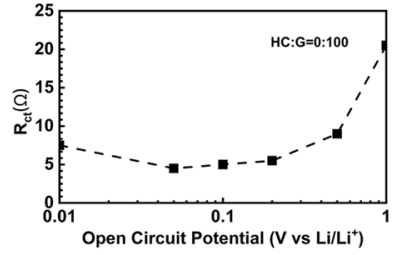

(b)

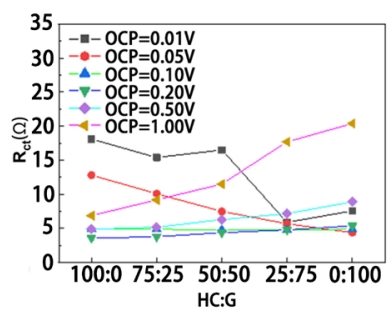

(c)

Figure 9. The charge transfer resistances as a function of ending open circuit potential for (a) Hard Carbon: Graphite (100:0) and (b) Hard Carbon: Graphite (0:100), respectively. (c) The charge transfer resistances as a function of Hard Carbon: Graphite ratio at various ending open circuit potential.

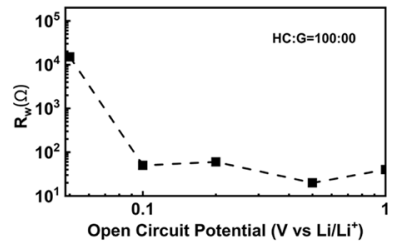

(a)

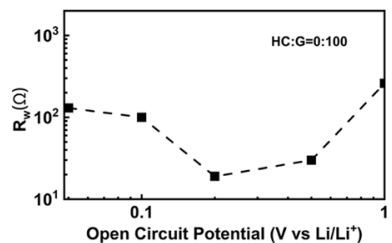

(b)

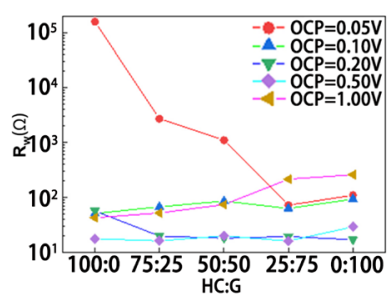

(c)

Figure 10. The Warburg resistances as a function of ending open circuit potential for (a) Hard Carbon: Graphite (100:0) and (b) Hard Carbon: Graphite (0:100), respectively. (c) The charge transfer resistances as a function of Hard Carbon: Graphite ratio at various ending open circuit potential. 
Warburg resistance with increasing ratio of hard carbon: graphite. At the ending potential of $0.20 \mathrm{~V}$ and $0.10 \mathrm{~V}$, respectively, the anode has the comparable Warburg resistance with various ratios of hard carbon: graphite. At the ending potential of $0.05 \mathrm{~V}$, the anode has higher charge transfer resistance with increasing hard carbon: graphite. The Warburg resistance at $0.01 \mathrm{~V}$ has unacceptable error bar so this data was not reported here.

The difference of charge transfer resistance and Warburg resistance may be attributed to the SOC evolution with the ending potential. Here, SOC is defined as the ratio of charged capacity to the full charged capacity, and the SOC at 0.01 $\mathrm{V}$ is defined as $100 \%$. As presented in Table 3, the SOC of mixed anodes at a series of potential ranging from $0.01 \mathrm{~V}$ to $1.50 \mathrm{~V}$ are different based on various hard carbon: graphite ratios. At the potential ranging from $0.01 \mathrm{~V}$ to $0.10 \mathrm{~V}$, the anodes with higher ratio of hard-carbon: graphite show lower SOC than that of anodes with lower ratio. However, at the potential ranging from $0.20 \mathrm{~V}$ to 1.00 $\mathrm{V}$, the anodes with higher ratio of hard-carbon: graphite show higher SOC than that of anodes with lower ratio. Here, there should be a reversal point of the SOC evolution between $0.10 \mathrm{~V}$ and $0.20 \mathrm{~V}$. The SOC evolution is mostly matched with the evolution of the charge transfer resistance difference in Figure 9 and the evolution of Warburg resistance in Figure 10. The SOC is corresponding to the level of anode lithiation, therefore the various levels of anode lithiation may result in the different charge transfer resistances and Warburg resistance. From the above results, the specific capacity evolution of mixed anodes at various potential range should be attributed to the lithiation level differences. The ohmic resistance and SEI layers (capacitances and resistances) should not be sensitive to the SOC after some initial cycles, so the Rs and the resistances and capacitances of SEI multi-layers $\left(R_{j}, j=1,2,3\right)$ are similar for different hard carbon-graphite shown in Table 2.

In summary, the above results indicate a power-energy coupling effect of mixed anode: 1) At the rates lower than $0.2 \mathrm{C}$, the mixed anodes with lower hard carbon: graphite ratio exhibit the higher energy performance without losing the power performance. At the rates higher than $0.5 \mathrm{C}$, the mixed anodes with higher hard carbon: graphite ratio exhibit the higher energy performance with the comparable power performance. 2) The mixed anodes with higher ratio of hard-carbon: graphite is advantageous if working in the potential range with the

Table 3. The SOC of the mixed anode cells at various potential.

\begin{tabular}{|c|c|c|c|c|c|c|}
\hline \multirow{2}{*}{ Ratios } & \multicolumn{6}{|c|}{ Anode Potential vs $\mathrm{Li} / \mathrm{Li}^{+}(\mathrm{V})$} \\
\hline & 0.01 & 0.05 & 0.10 & 0.20 & 0.50 & 1.00 \\
\hline HC: G (100:0) & $100 \%$ & 76.0 & $64.3 \%$ & $50.4 \%$ & $25.8 \%$ & $3.8 \%$ \\
\hline HC: G $(75: 25)$ & $100 \%$ & 79.1 & $58.7 \%$ & $39.5 \%$ & $19.9 \%$ & $1.8 \%$ \\
\hline HC: G (50:50) & $100 \%$ & 84.7 & $55.4 \%$ & $30.5 \%$ & $12.9 \%$ & $0.4 \%$ \\
\hline HC: G (25:75) & $100 \%$ & 86.0 & $46.5 \%$ & $17.5 \%$ & $6.4 \%$ & $0.4 \%$ \\
\hline HC: G $(0: 100)$ & $100 \%$ & 88.1 & $42.1 \%$ & $9.0 \%$ & $2.6 \%$ & $0.2 \%$ \\
\hline
\end{tabular}


ending potential higher than $0.10 \mathrm{~V}$; the ratio of hard-carbon: graphite should be designed according to the required rates if working in the potential range with the ending potential lower than 0.10 V. 3) The power-energy coupling effect may be attributed to charge transfer resistance evolution. The structure and conductivity difference of the hard carbon and graphite result in their specific potential capacity profiles at various rates. The difference of potential capacity profiles is corresponding to the electrode lithiation level evolution which affects the charge transfer resistance and Warburg resistance. From a practical point view, the final (power) performance of a cell should be determined by the combination of all resistances including ohmic resistance, SEI layer, the charge transfer resistance, and Warburg element. Therefore, we can design the mixed anodes with the specific energy-power requirements by controlling the ratio of hard carbon: graphite.

\section{Conclusion}

In summary, we have well designed a series of mixed anodes with various ratios of hard carbon and graphite, which show the potential profiles with the shape combined of sloping characteristics of hard carbon and platform characteristics of graphite. The mixed anodes show lower specific capacity with increasing hard carbon content at the low rates, while showing higher specific capacity with the increasing hard carbon content at the high rates. Furthermore, their specific capacity evolution is studied in different split potential ranges. With the aid of EIS, we found that the capacity evolution with mixed ratio is attributed to the lithiation-level induced difference of charge transfer resistance and Warburg resistance. The ohmic resistance and SEI layers (capacitances and resistances) were verified not sensitive to the SOC after some initial cycles. These results present the new quantified approach to design the mixed anodes for the balance of energy and power performance of the $\mathrm{Li}$-ion batteries.

\section{Acknowledgements}

This work was supported by US Army Research Laboratory under contract No. W911NF-15-2-0103 and Office of Naval Research under contract No. N00014-17-1-2650.

\section{Conflicts of Interest}

The authors declare no conflicts of interest regarding the publication of this paper.

\section{References}

[1] Aurbach, D., Levi, M.D., Levi, E. and Schechter, A. (1997) Failure and Stabilization Mechanisms of Graphite Electrodes. The Journal of Physical Chemistry B, 101, 2195-2206. https://doi.org/10.1021/jp962815t

[2] Fong, R., Vonsacken, U. and Dahn, J.R. (1990) Studies of Lithium Intercalation into 
Carbons Using Nonaqueous Electrochemical Cells. Journal of the Electrochemical Society, 137, 2009-2013. https://doi.org/10.1149/1.2086855

[3] Goodenough, J.B. and Kim, Y. (2010) Challenges for Rechargeable Li Batteries. Chemistry of Materials, 22, 587-603. https://doi.org/10.1021/cm901452z

[4] Tarascon, J.M. and Armand, M. (2001) Issues and Challenges Facing Rechargeable Lithium Batteries. Nature, 414, 359-367. https://doi.org/10.1038/35104644

[5] Sivakkumar, S.R. and Pandolfo, A.G. (2012) Evaluation of Lithium-Ion Capacitors Assembled with Pre-Lithiated Graphite Anode and Activated Carbon Cathode. Electrochimica Acta, 65, 280-287. https://doi.org/10.1016/j.electacta.2012.01.076

[6] Kim, J., Kim, J., Lim, Y., Lee, J. and Kim, Y. (2011) Effect of Carbon Types on the Electrochemical Properties of Negative Electrodes for Li-Ion Capacitors. Journal of Power Sources, 196 10490-10495. https://doi.org/10.1016/j.jpowsour.2011.08.081

[7] Ren, W., Zhang, Z., Wang, Y., Kan, G., Tan, Q., Zhong, Z. and Su, F. (2015) Preparation of Porous Carbon Microspheres Anode Materials from Fine Needle Coke Powders for Lithium-Ion Batteries. RSC Advances, 5, 11115-11123. https://doi.org/10.1039/C4RA15321A

[8] Haruna, H., Itoh, S., Horiba, T., Seki, E. and Kohno, K. (2011) Large-Format Lithium-Ion Batteries for Electric Power Storage. Journal of Power Sources, 196, 7002-7005. https://doi.org/10.1016/j.jpowsour.2010.10.045

[9] Zheng, T., Xue, J.S. and Dahn, J.R. (1996) Lithium Insertion in Hydrogen-Containing Carbonaceous Materials. Chemistry of Materials, 8, 389-393.

https://doi.org/10.1021/cm950304y

[10] Nishi, Y. (2000) Carbonaceous Materials for Lithium Ion Secondary Battery Anodes. Molecular Crystals and Liquid Crystals Science and Technology. Section A. Molecular Crystals and Liquid Crystals, 340, 419-424. https://doi.org/10.1080/10587250008025503

[11] Horiba, T., Maeshima, T., Matsumura, F., Koseki, M., Arai, J. and Muranaka, Y. (2005) Applications of High Power Density Lithium Ion Batteries. Journal of Power Sources, 146, 107-110. https://doi.org/10.1016/j.jpowsour.2005.03.205

[12] Gnanaraj, J.S., Levi, M.D., Levi, E., Salitra, G., Aurbach, D., Fischer, J.E. and Claye, A. (2001) Comparison between the Electrochemical Behavior of Disordered Carbons and Graphite Electrodes in Connection with Their Structure. Journal of the Electrochemical Society, 148, A525-A536. https://doi.org/10.1149/1.1368096

[13] Flandrois, S. and Guerin, K. (2000) On the Choice of Carbon Materials at the Negative Electrode of Li-Ion Batteries: Graphite vs. Hard Carbons. Molecular Crystals and Liquid Crystals Science and Technology. Section A. Molecular Crystals and Liquid Crystals, 340, 493-498. https://doi.org/10.1080/10587250008025514

[14] Kim, K., Lee, T., Kim, H., Lim, S. and Lee, S. (2014) A Hard Carbon/Microcrystalline Graphite/Carbon Composite with a Core-Shell Structure as Novel Anode Materials for Lithium-Ion Batteries. Electrochimica Acta, 135, 27-34.

https://doi.org/10.1016/j.electacta.2014.04.171

[15] Wu, B., Liu, T., Xia, Q. and Wu, X. (2013) Hard Carbon with Nano-Graphite Domain as High Performance Anode Material for Lithium-Ion Batteries. Journal of the Electrochemical Society, 160, A1720-A1724. https://doi.org/10.1149/2.042310jes

[16] Wang, J.S., Sherman, E., Verbrugge and Liu, M.P. (2011) Composite Electrodes of Disordered Carbon and Graphite for Improved Battery State Estimation with $\mathrm{Mi}$ nimal Performance Penalty. Journal of Power Sources, 196, 9648-9653.

https://doi.org/10.1016/j.jpowsour.2011.07.023 
[17] Yin, Y., Liu, C. and Fan, S. (2012) Well-Constructed CNT Mesh/PANI Nanoporous Electrode and Its Thickness Effect on the Supercapacitor Properties. The Journal of Physical Chemistry C, 116, 26185-26189. https://doi.org/10.1021/jp3083387

[18] Yin, Y., Liu, C. and Fan, S. (2016) Method for Making Carbon Nanotube Composite Structure. US 9434815 B2. https://patents.google.com/patent/US9434815B2/en

[19] Ender, M., Illig, J. and Ivers-Tiffée, E. (2017) Three-Electrode Setups for Lithium-Ion Batteries. Journal of the Electrochemical Society, 164, A71-A79. https://doi.org/10.1149/2.0231702jes

[20] Costard, J., Ender, M., Weiss, M. and Ivers-Tiffee, E. (2017) Three-Electrode Setups for Lithium-Ion Batteries. Journal of the Electrochemical Society, 164, A80-A87. https://doi.org/10.1149/2.0241702jes 